\title{
Identifikasi dan Potensi Senyawa Metabolit Sekunder Pada Akar Tumbuhan Saluang Belum (Lavanga sarmentosa (Blume) Kurz) Sebagai Afrodisiak
}

\author{
Meileli Florida Anggriani \\ Guru SMK Negeri 4 Palangka Raya, Kalimantan Tengah, Indonesia
}

\begin{abstract}
Abstrak : Saluang belum (Lavanga sarmentosa (Blume) Kurz) merupakan salah satu tumbuhan endemik Kalimantan Tengah yang telah sejak lama dikenal dan dimanfaatkan oleh masyarakat lokal sebagai obat tradisional untuk menyembuhkan beberapa macam penyakit seperti sakit pinggang dan ginjal serta sebagai penambah vitalitas. Cara pemanfaatannya adalah dengan mengkonsumsi air rebusan akar tumbuhan tersebut. Penelitian ini bertujuan mengetahui golongan senyawa metabolit sekunder yang terkandung dalam ekstrak kloroform akar tumbuhan Saluang Belum (Lavanga sarmentosa (Blume) Kurz ) dan potensinya untuk dikembangkan sebagai zat Afrodisiak. Proses identifikasi dimulai dengan melakukan ekstraksi, yaitu $1 \mathrm{Kg}$ serbuk akar tumbuhan saluang belum dimaserasi dengan menggunakan pelarut kloroform selama 3 X 24 jam, ekstrak hasil maserasi berupa ekstrak kloroform yang dipekatkan dengan rotary evaporator. Ekstrak klorofrom yang dihasilkan sebanyak 16 gram. Isolasi dilanjutkan dengan proses Kromatografi Lapis Tipis terhadap ekstrak kloroform dengan menggunakan eluen campuran dari kloroform dan n-heksan. Pemisahan dilanjutkan dengan Kromatografi kolom. Identifikasi golongan senyawa metabolit sekunder dilakukan dengan reaksi uji warna. Hasil penelitian bahwa berdasarkan hasil uji warna akar tumbuhan saluang belum mengandung senyawa metabolit sekunder golongan steroid dan flavonoid, serta eluen terbaik untuk estraksi adalah campuran kloroform dan n-heksan dengan komposisi 4:1. Senyawa aktif steroid dan flavonoid berpotensi sebagai afrodisiak. Diperlukan penelitian lebih lanjut untuk menyempurnakan hasil penelitian ini.
\end{abstract}

\section{Kata kunci: Akar, Saluang Belum, metabolit sekunder, afrodisiak.}

\section{Pendahuluan}

Indonesia merupakan salah satu negara yang memiliki kawasan hutan tropis yang sangat luas dengan beraneka ragam kekhasan genetik di dalamnya. Salah satu daerah yang memiliki kawasan hutan tropis yang cukup luas adalah Propinsi Kalimantan Tengah.

Penelitian di bidang fitokimia tanaman asli Indonesia telah dimulai oleh Greshoff pada tahun 1888. Saat ini, penelitian fitokimia lebih ditujukan pada kegiatan survei kimia dan bidang farmakologi. Penelitian dilakukan terhadap tumbuhan dimaksudkan untuk menentukan jenis golongan senyawa aktif yang terkandung di dalam tumbuhan tersebut, misalnya: alkaloid, flavonoid, lemak, zat warna dan sebagainya (Soediro, 1999). Lebih lanjut menurut Ciptadi (1994), penelitian yang sistematis terhadap kandungan senyawa dalam tumbuhan perlu dilakukan sehingga diperoleh informasi yang dapat membantu para ahli dalam memahami keadaan ilmiah yang sebenarnya dari senyawa tersebut. Dalam rangka 
penemuan dan pemanfaatan senyawa kimia yang terkandung dalam sumber daya hayati tersebut perlu dilakukan penelitian yang terencana dan berkelanjutan.

Selanjutnya Idah (2001), telah melakukan penelitian terhadap kandungan senyawa metabolit sekunder dalam ekstrak n-heksan pada kulit akar tumbuhan saluang belum sebagai tanaman obat tradisional Kalimantan Tengah yang memperoleh hasil, bahwa untuk memisahkan senyawa metabolit sekunder yang ada digunakan eluen n-heksan dan kloroform dengan perbandingan 5:1. Diketahui pula dalam ekstrak n-heksan kulit akar tumbuhan saluang belum terkandung senyawa berupa golongan flavonoid dan saponin.

Saluang belum (Lavanga sarmentosa (Blume) Kurz) merupakan salah satu tumbuhan endemik Kalimantan Tengah yang telah sejak lama dikenal dan dimanfaatkan oleh masyarakat lokal sebagai obat tradisional untuk menyembuhkan beberapa macam penyakit seperti sakit pinggang dan ginjal serta sebagai penambah vitalitas. Cara pemanfaatannya adalah dengan mengkonsumsi air rebusan akar tumbuhan tersebut. Penelitian ini bertujuan mengetahui golongan senyawa metabolit sekunder yang terkandung dalam ekstrak kloroform akar tumbuhan Saluang Belum (Lavanga sarmentosa (Blume) Kurz ) dan potensinya untuk dikembangkan sebagai zat Afrodisiak (Zat yang mampu meningkatkan gairah seksual/ vitalitas).

\section{Metode Penelitian}

Penelitian ini merupakan penelitian eksploratif dengan pendekatan laboratorium yang dilakukan melalui serangkaian percobaan. Proses dimulai maserasi serbuk halus akar tumbuhan saluang belum dengan pelarut kloroform pada suhu kamar dalam wadah berpenutup selama 3 x 24 jam. Kemudian disaring menggunakan kertas saring meghasilkan filtrat dan residu. Filtrat yang diperoleh diuapkan dengan menggunakan rotary evaporator sampai diperoleh ekstrak kental (padat). Ekstrak kloroform yang dihasilkan sebanyak 16 gram.

Ekstrak kloroform ini digunakan dalam proses Kromatografi Lapis Tipis (KLT) untuk mengetahui jumlah senyawa dan komposisi eluen yang terbaik untuk memisahkan senyawa yang terkandung dalam ekstrak kloroform akar tumbuhan saluang belum. KLT dilakukan dengan memvariasikan komposisi eluen dari campuran kloroform dan n-heksan dalam berbagai perbandingan volume. Kromatogram dengan pola pemisahan yang terbaik, komposisi eluennya digunakan sebagai fasa gerak dalam proses kromatografi kolom.

Ekstrak kloroform yang telah kering, dilarutkan dalam campuran kloroform dan aquadest (1:1) menjadi $4 \mathrm{~mL}$ larutan, kemudian dibiarkan terpisah sampai terbentuk dua lapisan yaitu lapisan kloroform dan lapisan air. Lapisan kloroform digunakan untuk identifikasi senyawa terpenoid, steroid dan alkaloid, sedangkan lapisan air digunakan untuk identifikasi senyawa flavonoid, fenolik dan saponin. 


\section{Hasil Penelitian dan Pembahasan}

Komponen yang terdapat dalam ekstrak kloroform akar tumbuhan saluang belum dipisahkan melalui proses kromatografi lapis tipis (KLT) dengan menggunakan eluen dengan tingkat kepolaran yang berbeda. Tujuan dari variasi kepolaran eluen ini adalah untuk memperoleh komposisi eluen yang terbaik untuk memisahkan komponen yang terdapat dalam ekstrak kloroform akar tumbuhan saluang belum. Eluen yang digunakan adalah campuran kloroform dan n-heksan. Kloroform adalah pelarut semi polar dan n-heksan merupakan pelarut non polar. Perbandingan kloroform dan n-heksan yang digunakan adalah: $(9: 1),(8: 2)$, (7 : 3), (6:4), (4:6), (3:7), (2:8), (1:9), dengan urutan tingkat kepolaran sebagai berikut: $(1: 9)<(2: 8)<(3: 7)<(4: 6)<(6: 4)<(7: 3)<(8: 2)<(9: 1)$.

Pemisahan yang baik yang dimaksudkan adalah bahwa senyawa-senyawa yang terdapat dalam ekstrak kloroform akar tumbuhan saluang belum dapat terpisah sempurna. Pemisahan yang sempurna dapat dilihat dari tidak bertumpuknya noda dalam kromatogram dan jauhnya jarak antar noda. Hal ini dimaksudkan agar dalam proses kromatografi kolom senyawa-senyawa dapat dipisahkan dan saat senyawa dari setiap fraksi di KLT akan diperoleh satu noda. Pola pemisahan pada kromatogram dilihat dengan menggunakan sinar lampu UV pada panjang gelombang $254 \mathrm{~nm}$ dan $366 \mathrm{~nm}$. Pada panjang gelombang $254 \mathrm{~nm}$ komponen-komponen ekstrak terlihat lebih jelas dibandingkan pada $366 \mathrm{~nm}$, maka panjang gelombang yang digunakan adalah $254 \mathrm{~nm}$. Hasil pemisahan dengan kromatografi lapis tipis dimuat pada Tabel 1.

\section{Tabel 1. Data Hasil Pemisahan Ekstrak Kloroform Pada Akar Tumbuhan Saluang Belum dengan Metode Kromatografi Lapis Tipis (KLT) Menggunakan Eluen Kloroform dan n-heksan}

\begin{tabular}{ccccccccc}
\hline $\begin{array}{c}\text { Kloroform: } \\
\text { n-heksan }\end{array}$ & $\begin{array}{c}\mathbf{J u m l a h} \\
\text { noda }\end{array}$ & $\mathbf{R f}_{\mathbf{1}}$ & $\mathbf{R f}_{\mathbf{2}}$ & $\mathbf{R f}_{\mathbf{3}}$ & $\mathbf{R f}_{\mathbf{4}}$ & $\mathbf{R f}_{\mathbf{5}}$ & $\mathbf{R f}_{\mathbf{6}}$ & $\mathbf{R f}_{\mathbf{7}}$ \\
\hline $1: 9$ & 1 & 0,016 & - & - & - & - & - & - \\
$2: 8$ & 1 & 0,039 & - & - & - & - & - & - \\
$3: 7$ & 2 & 0,125 & 0,078 & - & - & - & - & - \\
$4: 6$ & 3 & 0,313 & 0,156 & 0,063 & - & - & - & - \\
$6: 4$ & 5 & 0,397 & 0,333 & 0,254 & 0,079 & 0,032 & - & - \\
$7: 3$ & 4 & 0,419 & 0,355 & 0,097 & 0,032 & - & - & - \\
$8: 2$ & 4 & 0,683 & 0,452 & 0,269 & 0,071 & - & - & - \\
$9: 1$ & 7 & 0,800 & 0,646 & 0,546 & 0,400 & 0,177 & 0,153 & 0,100 \\
\hline
\end{tabular}

Dari hasil KLT dengan 8 (delapan) variasi komposisi eluen (kloroform : nheksan), masing- masing komposisi menghasilkan jumlah noda yang berbedabeda dengan pola pemisahan yang cukup baik. Berdasarkan Tabel 1.1 hubungan faktor retensi (Rf) dengan komposisi eluen dialurkan pada kurva seperti Gambar 1.1 


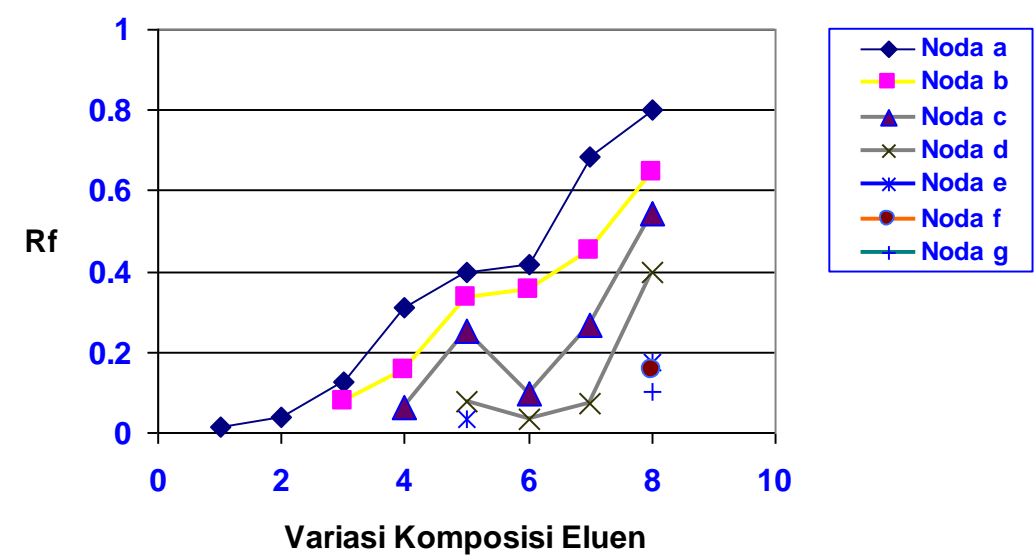

$1=1: 9$

$2=2: 8$

$3=3: 7$

$4=4: 6$

$5=6: 4$

$6=7: 3$

$7=8: 2$

$8=9: 1$

\section{Gambar 1. Grafik Hubungan Antara Variasi Komposisi Eluen (kloroform : n-heksan) dengan harga $\mathrm{Rf}$}

Dari gambar 1.1 tampak bahwa variasi komposisi eluen dengan tingkat kepolaran yang berbeda menghasilkan jarak noda yang berbeda. Dari gambar tersebut dapat dikatakan bahwa semakin bertambahnya kepolaran eluen semakin besar jarak nodanya, sehingga semakin baik pemisahannya, tetapi harus tetap dilihat pola pemisahannya. Terlihat pula dengan jelas bahwa dengan semakin meningkatnya kepolaran eluen cenderung mengakibatkan kenaikkan harga Rf.

Komponen-komponen yang terdapat pada ekstrak kloroform akar tumbuhan saluang belum tersebut dipisahkan kembali dengan kromatografi kolom. Proses ini menggunakan eluen terbaik dari tahap KLT yaitu kloroform : nheksan dengan komposisi 4: 1. Dengan kepolaran pelarut yang cukup besar, maka diharapkan dapat menghasilkan pola pemisahan yang baik dan dapat mengisolasi senyawa yang diharapkan. Besarnya kepolaran pelarut didasarkan pada lebih besarnya volume kloroform yang sifatnya lebih polar daripada n-heksan.

Pengujian golongan metabolit sekunder dari ekstrak akar tumbuhan saluang belum dilakukan melalui uji warna. Pengujian ini didasarkan pada sifat kimia dari setiap kelompok senyawa metabolit sekunder. Umumnya setiap kelompok senyawa metabolit sekunder memiliki gugus fungsi sebagai gugus pengenal yang khas dan akan memberikan reaksi kimia yang khas pula. Dalam penelitian ini dilakukan uji terhadap golongan metabolit sekunder, yaitu: steroid, fenolik, kumarin, saponin, flavonoid, dan terpenoid. Hasil uji warna golongan senyawa metabolit sekunder ekstrak kloroform akar tumbuhan saluang belum ditampilkan pada Tabel 2. 
Tabel 2. Hasil Identifikasi Kandungan Senyawa Metabolit Sekunder Ekstrak Kloroform Pada Akar Tumbuhan Saluang Belum (Lavanga sarmentosa (Blume) Kurz)

\begin{tabular}{|c|c|c|c|}
\hline Uji & Identifikasi & Hasil & Keterangan \\
\hline Steroid & $\begin{array}{l}\text { Lapisan etil asetat }+ \text { asam } \\
\text { asetat anhidrat }+ \text { asam sulfat }\end{array}$ & $\begin{array}{c}\text { Terbentuk warna biru } \\
\text { ungu }\end{array}$ & + \\
\hline Terpenoid & $\begin{array}{l}\text { Lapisan etil asetat + asam } \\
\text { sulfat }\end{array}$ & $\begin{array}{l}\text { Tidak terbentuk } \\
\text { warna merah }\end{array}$ & - \\
\hline Flavanoid & $\begin{array}{c}\text { Lapisan air }+ \text { serbuk logam } \mathrm{Mg} \\
+\mathrm{HCl}\end{array}$ & $\begin{array}{l}\text { Terbentuk warna } \\
\text { orange }\end{array}$ & + \\
\hline Fenolik & Lapisan air $+\mathrm{FeCl}_{3}$ & $\begin{array}{l}\text { Tidak terbentuk } \\
\text { cincin warna biru }\end{array}$ & - \\
\hline Saponin & $\begin{array}{l}\text { Lapisan air dikocok } \\
\text { kuat-kuat }\end{array}$ & $\begin{array}{c}\text { Tidak terbentuk busa } \\
\text { parmanen } \\
( \pm 15 \text { menit })\end{array}$ & - \\
\hline
\end{tabular}

Pada pengujian steroid, ekstrak kloroform yang dimasukkan ke dalam lubang pelat tetes dan ditambahkan asam sulfat dan asam asetat anhidrat berubah warna menjadi biru-ungu yang menandakan adanya steroid. Untuk pengujian flavonoid, pada penambahan logam $\mathrm{Mg}$ dan $\mathrm{HCl}$ terhadap lapisan air dari ekstrak kloroform terjadi perubahan warna menjadi orange yang menandakan adanya flavonoid dalam ekstrak kloroform tersebut. Untuk uji kandungan senyawa metabolit sekunder yang lain, hasil reaksi memberikan hasil yang negatif, yaitu untuk senyawa golongan: saponin, kumarin, terpenoid, dan fenolik.

\section{Kesimpulan}

Komposisi eluen terbaik campuran kloroform dan n-heksan untuk memisahkan senyawa metabolit sekunder dalam ekstrak kloroform akar tumbuhan saluang belum (Lavanga sarmentosa (Blume) Kurz) adalah 4 : 1. Senyawa metabolit sekunder yang terkandung dalam ekstrak kloroform akar tumbuhan saluang belum berdasarkan hasil reaksi uji warna adalah golongan steroid dan flavonoid. Kandungan metabolit sekunder yang ada berpotensi sebagai zat Afrodisiak.

\section{Daftar Pustaka}

Achmad, S.A. 1995. Keanekaragaman Hayati Indonesia. Jakarta: Universitas Indonesia

Anwar, C., Purwanto, W., Pranomo, H.D., Wahyuningsih, T. W. 1994. Pengantar Praktikum Kimia Organik. Jogjakarta: Departemen Pendidikan dan Kebudayaan. 
Arbain, D. 1995. Uji Bioaktivitas dan Penelitian Kimia Bahan Alam, Makalah Lokakarya Isolasi Senyawa Berkhasiat. Padang: HEDS-JICA FMIPA UNAND.

Backer, C. A, Bakhuizen, R. C. 1965. Flora of Java vol. 11. The Netherlands : N. V. P. Noordhoff.

Ciptadi. 1994. Beberapa Senyawa Kimia Dari Kulit Batang Morus Macroura Miq. Laporan Penelitian tidak diterbitkan. Palangkaraya: Lemlit UNPAR.

. 1995. Isolasi dan Identifikasi Kandungan Senyawa Kimia dari Tanaman Moraceae. Lemlit UNPAR, Laporan Penelitian tidak diterbitkan. Palangkaraya: FKIP UNPAR.

..1997. Dasar-Dasar Ekstraksi. Kimia Organik Bahan Alam. Diktat tidak diterbitkan. Palangkaraya: FKIP UNPAR.

Idah 2001. Isolasi dan Identifikasi Komponen-Komponen Metabolit Sekunder Ekstrak n-heksan Kulit Akar Tumbuhan Saluang Belum (Lavanga sarmentosa (Blume)Kurz). Skripsi tidak diterbitkan. Palangkaraya : UNPAR.

Lehninger. 1982. Dasar-dasar Biokimia Jilid 3 (Terjemahan). Jakarta: Erlangga.

Majang, Y. 1995. Terpenoid dan Steroid. Palembang: Universitas Andalas.

Ndadari, S. 2005. Isolasi dan Identifikasi Komponen-Komponen Metabolit Sekunder Ekstrak n-heksan Pada Batang Tumbuhan Kamunah (Croton tiglium L.). Skripsi tidak diterbitkan. Palangkaraya: UNPAR.

Pudjaatmaka, H. 2000. Kamus Kimia. Jakarta: Balai Pustaka.

Robinson,T. 1991. Kandungan Organik Tumbuhan Tinggi (Terjemahan). Bandung: ITB.

Sastrohadmajojo, H. 1998. Kromatografi. Jogjakarta: Liberty.

Soediro, S. 1999. Kandungan Senyawa Bioaktif dari Tumbuhan dan Cara Analisisnya, Makalah Yang Disampaikan Pada Lokakarya Pelatihan Pemanfaatan Senyawa Metabolit Sekunder Asal Tumbuhan Sebagai Insektisida. Bengkulu: HEDS-JICA FMIPA UNIB.

Soekamto, N. H., Achmad, S. A., Ghisalberti, E. L., Hakim, E. H., Syah, Y. M., 2002. Mulberin dan Mulbrerokromen Dua Senyawa Bioaktif dari Artocarpusfretessi, Bull. Soc. Nat. Prod. Chem. (Indonesia), 2, 45, 50.

Stahl, Egon. 1985. Analisis Obat Secara Kromatografi dan Makroskopi. Bandung: ITB Bandung.

Sudjadi.1986. Metode Pemisahan. Jogjakarta: Kanisius.

Taslim. 1999. Survei Fitokimia Tumbuhan Obat Kontrasepsi Tradisional Kalimantan Tengah. Palangkaraya: UNPAR.

Tjitrosoepomo, G. 1994. Taksonami Tumbuhan Obat-Obatan. Jogjakarta: Gajahmada University Press. 